\title{
Comparison of irisin hormone expression between thyroid cancer tissues and oncocytic variant cells
}

This article was published in the following Dove Press journal: Cancer Management and Research

\author{
Kader Ugur' \\ Suleyman Aydin ${ }^{2}$ \\ Tuncay Kuloglu ${ }^{3}$ \\ Gokhan Artas ${ }^{4}$ \\ Mehmet Ali Kocdor ${ }^{5}$ \\ İbrahim Sahin ${ }^{2,6}$ \\ Meltem Yardim² \\ İbrahim Hanefi Ozercan ${ }^{4}$ \\ 'Department of Endocrinology and \\ Metabolism Disease, School of Medicine, \\ Firat University, Elazig, Turkey; \\ ${ }^{2}$ Department of Medical Biochemistry \\ and Clinical Biochemistry (Firat \\ Hormones Research group), Firat \\ University Hospital, Elazig, Turkey; \\ ${ }^{3}$ Department of Histology and \\ Embryology, School of Medicine, Firat \\ University, Elazig, Turkey; ${ }^{4}$ Department of \\ Pathology, School of Medicine, Firat \\ University, Elazig, Turkey; ${ }^{5}$ Department of \\ General Surgery, School of Medicine, \\ Dokuz Eylul University, İzmir, Turkey; \\ ${ }^{6}$ Department of Medical Biology, School \\ of Medicine, Erzincan Binali Yildirim \\ University, Erzincan, Turkey
}

Objective: The incidence of thyroid cancer has been continuously increasing. The main objective of this study was to investigate irisin expression in various thyroid pathologies and to compare these expression patterns with irisin expression in healthy thyroid tissues.

Methods: The study groups consisted of 20 cases each of control thyroid tissue, Hashimoto's thyroiditis, thyroid papillary carcinoma, oncocytic papillary carcinoma, follicular thyroid carcinoma, oncocytic follicular thyroid carcinoma, medullary thyroid carcinoma, anaplastic thyroid carcinoma. Irisin expression was evaluated using immunohistochemistry. Irisin levels in thyroid tissue supernatants were measured using ELISA.

Results: Patients with HT showed increased irisin expression compared with controls $(p<0.05)$. In addition, mild immunoreactivity was observed in the thyroid tissues of patients with papillary carcinoma while significantly increased irisin immunoreactivity was observed tissues of patients with oncocytic papillary carcinoma $(p<0.05)$. There was no difference in irisin immunoreactivity in thyroid tissues between patients with follicular carcinoma and controls. However, irisin immunoreactivity was higher in tissues of patients with oncocytic follicular carcinoma than in tissues of patients with follicular carcinoma $(p<0.05)$. No irisin immunoreactivity was observed in tissues of patients with medullary carcinoma, a malignant tumor the thyroid; however, irisin expression was significantly increased in tissues of patients with anaplastic carcinoma compared with that in tissues of controls $(p<0.05)$. Furthermore, in all thyroid tissues with irisin expression, irisin immunoreactivity was observed in follicular cells, indicating that irisin is produced by these cells.

Conclusion: Irisin is a novel potential immunohistochemical marker for differentiating oncocytic variants of papillary and FTCs from papillary and follicular thyroid cancers.

Keywords: thyroid cancer, irisin, immunohistochemistry, diagnostic biomarker

\section{Introduction}

Thyroid cancers are one of the most frequent endocrine diseases, which have shown an increasing incidence in recent years and involve various medical fields, such as endocrinology, nuclear medicine, surgery, radiology, radiotherapy, internal medicine, pharmacology, and medical biochemistry. ${ }^{1,2}$ Thyroid cancers account for approximately $1 \%$ of all cancers, causing 6-8 deaths from cancer per 1 million individuals. ${ }^{1}$ They are ranked 25 th among the most common cancers in the United States. ${ }^{3}$ Compared with other cancers, thyroid cancers are associated with increased probability of cure, increased survival, and generally well-differentiated histological
Correspondence: Suleyman Aydin Department of Medical Biochemistry and Clinical Biochemistry (Firat Hormones Research group), Firat University Hospital, Yunus Emre Street, Elazig 231 19 Turkey

Tel +905334934643

Fax +904242379138

Email saydin I@hotmail.com 
features. ${ }^{4}$ Papillary thyroid carcinoma (PTC) with its variants and follicular thyroid carcinoma (FTC) with its variants, poorly differentiated (eg, insular) and undifferentiated (anaplastic) thyroid carcinomas (ATC), all originate from follicular thyroid cell. Medullary thyroid carcinoma (MTC) develops from $\mathrm{C}$ cells in the thyroid gland, and is more aggressive and less differentiated than papillary or follicular cancers. Oncocytic thyroid carcinomas are Hurthle thyroid carcinomas. $^{5}$

Similar to other types of cancer, the physiopathological mechanisms underlying thyroid cancers have not been completely demonstrated so far despite advances in medicine. Some recent studies have reported upregulated or downregulated expressions of peptide-based hormones in thyroid cancers, indicating that these peptide-based hormones may play roles in the etiopathology of thyroid cancers. $^{6}$ For instance, some studies have reported increased ghrelin expression in papillary medullary thyroid cancer, while another study has reported increased obestatin expression in PTC. ${ }^{7-9}$ Some studies have reported an association of certain peptide-based hormones with thyroid cancers. $^{10,11}$

In our extensive literature review, we found no study investigating whether immunohistochemical expression of recently discovered peptide-based hormone irisin is associated with thyroid cancers. Irisin converts white adipose tissue into brown adipose tissue, allowing energy to dissipate in the form of heat. ${ }^{12}$ It is synthesized in many tissues and organs, including the skeleton, heart muscles, liver, blood cells, pancreas, spleen, and connective tissue. $^{13,14}$ Moreover, it is associated with many metabolic diseases, such as gestational diabetes, diabetes, and hepatosteatosis. $^{14-18}$

Some recent studies have reported increased irisin expression in gastrointestinal cancers. ${ }^{19}$ Circulating and immunohistochemical irisin levels in breast cancer are also found to be increased. ${ }^{20}$ Interestingly, anti-tumor properties of irisin were reported in a study of pancreatic and prostate cancer cell lines. ${ }^{21,22}$ Of note, increased irisin expression in cancer tissues has been implicated to cause the destruction of white adipose tissue, thereby leading to cancer cachexia. $^{23,24}$ Statistically significant overexpression of irisin was also found in patients with toxic goiter as compared to papillary thyroid cancer and controls. ${ }^{25}$ It has been also observed that neither physiological nor high physiological/pharmacological concentrations of irisin regulate cell adhesion and/or colony formation in human thyroid cancer cell lines. ${ }^{26}$ Taken together, these reports indicate a link between irisin expression and some cancer types. $^{19-22,27}$ Furthermore, thyroid is a thermogenic tissue, $^{28}$ and cancer cells are vulnerable to heat. ${ }^{29}$ The diagnosis of thyroid cancers is controversial, ${ }^{30}$ and no reliable diagnostic criteria have been established to date.

Therefore, the aim of this study was to investigate irisin expression in patients with Hashimoto's thyroiditis (HT), PTC, oncocytic papillary thyroid carcinoma (OPTC), FTC, oncocytic follicular thyroid carcinoma (OFTC), MTC, ATC, and control tissues using immunohistochemistry and ELISA to demonstrate the expression of irisin in thyroid cancers.

\section{Materials and methods}

Firat University Non-invasive Ethics Committee approved this study (No: 35; Date: June 4, 2016). All patients whose tissues were used in this research had provided written informed consent, and that this was conducted in accordance with the Declaration of Helsinki.

The archived pathology records were reviewed for thyroid tissues of body mass index- and age-matched patients. Tissues of patients with HT $(n=20)$, PTC $(n=20)$, OPTC $(n=20)$, FTC $(n=20)$, OFTC $(n=20)$, MTC $(n=20)$, and ATC $(n=20)$, diagnosed according to the WHO 2004 classification, $^{31}$ and healthy $(n=20)$ individuals were selected in the study. The control group was internally formed and comprised intact thyroid tissues of thyroid cancer patients. All thyroid tissue preparations were stained with hematoxylin, and compliance with the 2014 WHO classification was confirmed by an experienced pathologist who was blinded to the study. ${ }^{5,32}$ Here ATCs are undifferentiated, and medullary are usually less differentiated than papillary or follicular cancers and other remaining thyroid cancers included in the study were moderately differentiated thyroid tumors. Seven slides from each group were evaluated for irisin immunoreactivity.

\section{Immunohistochemistry}

We used the avidin-biotin peroxidase complex technique. ${ }^{33}$ Sections (thickness, 4-6 $\mu \mathrm{m}$ ) cut from paraffin blocks were mounted on polylysine slides. Deparaffinized specimens were washed with a series of alcohol solutions, and boiled in citrate buffer solution for $10 \mathrm{mins}$ in a microwave $(750 \mathrm{~W})$ at a $\mathrm{pH}$ of 6 for antigen retrieval. The specimens were cooled at room temperature for approximately $20 \mathrm{mins}$ after boiling, washed for $3 \times 5$ mins with PBS (P4417, Sigma-Aldrich, USA), and incubated with hydrogen peroxide block solution for 5 mins to prevent endogenous peroxidase activity 
(Hydrogen Peroxide Block, TA-125-HP, Lab Vision Corporation, USA). The specimens were washed with PBS for $3 \times 5$ mins, and treated with Ultra V Block (TA-125-UB, Lab Vision Corporation, USA) solution for 5 mins to prevent background staining. Then, the specimens were incubated with 1/200 diluted Irisin primary antibody (Rabbit Irisin primary antibody, H-067-17, Phoenix Pharmaceuticals, Inc., California, USA) in humid environment at room temperature for $60 \mathrm{~min}$. After primary antibody application, the specimens were washed with PBS for $3 \times 5$ mins and incubated with secondary antibody (biotinylated Goat AntiPolyvalent (anti-mouse/rabbit IgG), TP-125-BN, Lab Vision Corporation, USA) in humid environment at room temperature for 30 mins. After secondary antibody application, the specimens were washed with PBS for $3 \times 5$ mins and incubated with streptavidin peroxidase (TS-125-HR, Lab Vision Corporation, USA) in humid environment at room temperature for 30 mins. Next, the specimens were placed in PBS. 3-Amino-9-ethylcarbazole (AEC) substrate+AEC chromogen (AEC Substrate, TA-015 and HAS, AEC Chromogen, TA-002-HAC, Lab Vision Corporation, USA) solution was instilled on the specimens, and the slides were simultaneously washed with PBS after an image signal was obtained under light microscopy.

Primary antibodies were omitted as a negative control. The specimens were counterstained with Mayer's hematoxylin, washed with PBS and distilled water, and covered with an appropriate mounting medium (Large Volume Vision Mount, TA-125-UG, Lab Vision Corporation, USA). The slides were examined and photographed under a Leica DM500 microscope (Leica DFC295).

The H-score was calculated by semiquantitative assessment of both the intensity of staining, graded as: 0 , unstained; 1 , weak staining; 2 , medium staining; 3 , strong staining, and the percentage of stained cells. A total of 8-10 discrete foci in each section were examined at $400 \times$ to generate an average staining intensity and percentage of stained cells. The final $\mathrm{H}$-score was calculated using the formula: [( $1 \times$ percentage of weakly stained tumor cells $)$ $+(2 \times$ percentage of moderately stained tumor cells $)$ $+(3 \times$ percentage of intensely positive tumor cells $)] .{ }^{34}$

\section{Irisin measurement in all tissue samples}

Tissue samples from each series were homogenized as previously described. ${ }^{35}$ Irisin levels in all tissue sample supernatants were measured using Phoenix ELISA Irisin Kit as previously described. ${ }^{36}$

\section{Statistical analysis}

The collected data were presented as mean and standard deviation. SPSS Version 22 (IBM Corporation, Armonk, NY, USA) was used for statistical analyses. The independent samples $t$-test was used for paired comparison between the groups, and one-way ANOVA and Tukey post hoc test were used for the other comparisons. A $p<0.05$ was considered statistically significant.

\section{Results}

Immunohistochemical staining for irisin immunoreactivity was evaluated using light microscopy. Control thyroid tissues (H\&E staining; Figure 1A) and irisin immunoreactivity were observed in follicular cells of control thyroid tissues (Figure 1B). HT (H\&E staining; Figure 1C) and HT irisin immunoreactivity (Figure 1D) were also shown. Irisin immunoreactivity was increased in tissues of patients with HT compared with that in tissues of controls (Figure 1C and D) $(p<0.05)$.

Papillary carcinoma (H\&E staining; Figure 2A) and irisin immunoreactivity were mild in papillary carcinoma, which is one of the malignant tumors of the thyroid (Figure 2B). OPTC (H\&E staining; Figure 2C) and irisin immunoreactivity were significantly increased in OPTC (Figure 2D) compared with that in papillary carcinoma $(p<0.05)$.

Comparison of irisin expression in FTC (Figure 3A, $\mathrm{H} \& \mathrm{E}$ staining; Figure $3 \mathrm{~B}$ irisin staining) and FTC (oncocytic variant; Figure $3 \mathrm{C}, \mathrm{H} \& \mathrm{E}$ staining; Figure 3D irisin staining) is seen in Figure 3. Irisin immunoreactivity was significantly increased in oncocytic follicular carcinoma (Figure 3C) compared with that in follicular carcinoma $(p<0.05)$.

Comparison of irisin expression in MTC (Figure 4A, H\&E staining; Figure 4B irisin staining) and ATC (oncocytic variant; Figure 4C, H\&E staining; Figure 4D irisin staining) is seen in Figure 4. No irisin immunoreactivity was observed in medullary carcinoma, which is one of the malignant tumors of the thyroid (Figure 4B). Irisin immunoreactivity was significantly increased in anaplastic carcinoma (Figure 4D) compared with that in controls $(p<0.05)$.

Using ELISA, irisin levels were detected in tissues of control thyroid $(0.96 \pm 0.32$ per $\mathrm{mg}$ of tissue), HT (1.26 \pm 0.32 per mg of tissue), PTC (1.44 \pm 0.42 per $\mathrm{mg}$ of tissue), OPTC $(2.21 \pm 0.72$ per $\mathrm{mg}$ of tissue), FTC ( $1.1 \pm 0.38$ per $\mathrm{mg}$ of tissue), OFTC $(4.35 \pm 1.13$ per $\mathrm{mg}$ of tissue), MTC (0.05 per $\mathrm{mg}$ of tissue), and ATC 

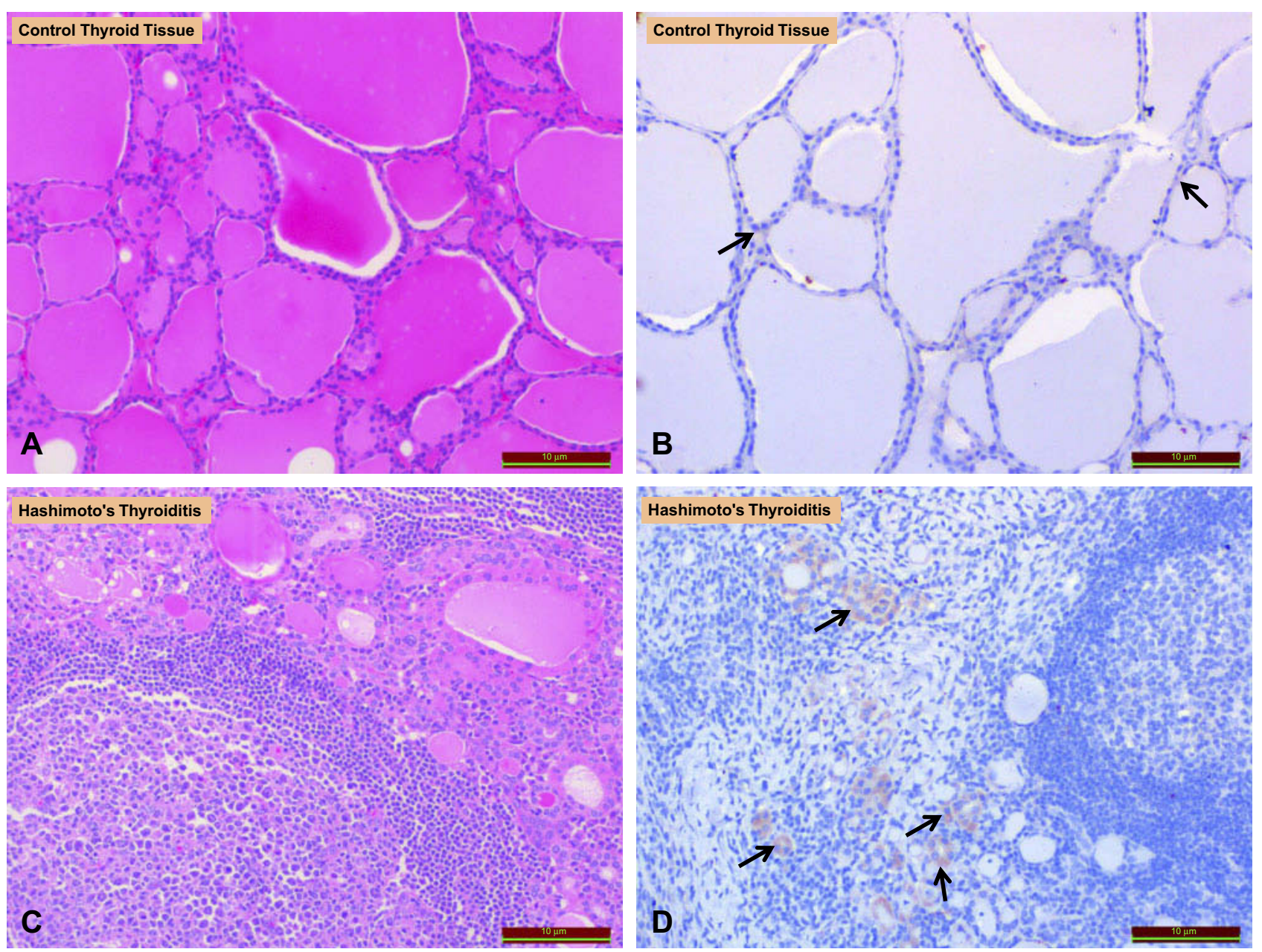

Figure I Comparison of irisin expression in hashimoto's thyroiditis and thyroid tissues of controls. (A) Control thyroid tissues (H\&E staining). (B) Control thyroid tissues (irisin staining). (C) Hashimoto's thyroiditis (H\&E staining). (D) Hashimoto's thyroiditis (irisin staining). Arrows show irisin immunoreactivity (black arrows).

(2.94 \pm 0.86 per $\mathrm{mg}$ of tissue). Irisin levels in thyroid tissue series and their comparisons are presented in Table 1.

\section{Discussion}

Thyroid cancers are the most common cancers of the endocrine system, with a steady increase in the incidence rate. ${ }^{1}$ Various genetic and epigenetic (changes in gene expression) factors play a role in thyroid cancers, ${ }^{37}$ although their etiopathology has not been fully elucidated. In this study, we immunohistochemically investigated irisin expression in various thyroid pathologies. Irisin is a new member of the endocrine system whose expression first demonstrated in the skeletal muscle, followed by many tissues, including thyroid tissue. ${ }^{13}$

In this study, irisin expression was significantly increased in tissues of patients with HT compared with that in controls. HT is an autoimmune disease of the thyroid gland characterized by non-microbial inflammation or an inflammation-like course. In other words, immune system produces antibodies against the thyroid cells that are recognized as foreign, thereby causing inflammation. ${ }^{38}$ Levels of irisin-a peptide associated with metabolic conditions - increase in inflammatory conditions. ${ }^{39}$ Therefore, increase in irisin levels in thyroid tissues of patients with HT reported in this study is likely to be due to inflammation. In contrast to our study by Uc and his coworkers show increased irisin expression in thyroids of Hashimoto disease patients even though they have not analyzed irisin expression in Hashimoto disease thyroid tissues. ${ }^{40}$ Moreover, irisin levels reportedly increase in tissues of patients with acute appendicitis, which is clinically associated with inflammation. ${ }^{41}$ This suggests that irisin levels will increase in inflammatory diseases, such as Hashimoto's disease, as reported in the present study.

Increased irisin levels in inflammation, including Hashimoto's disease, may reduce or eliminate inflammation because irisin has recently been reported to show 

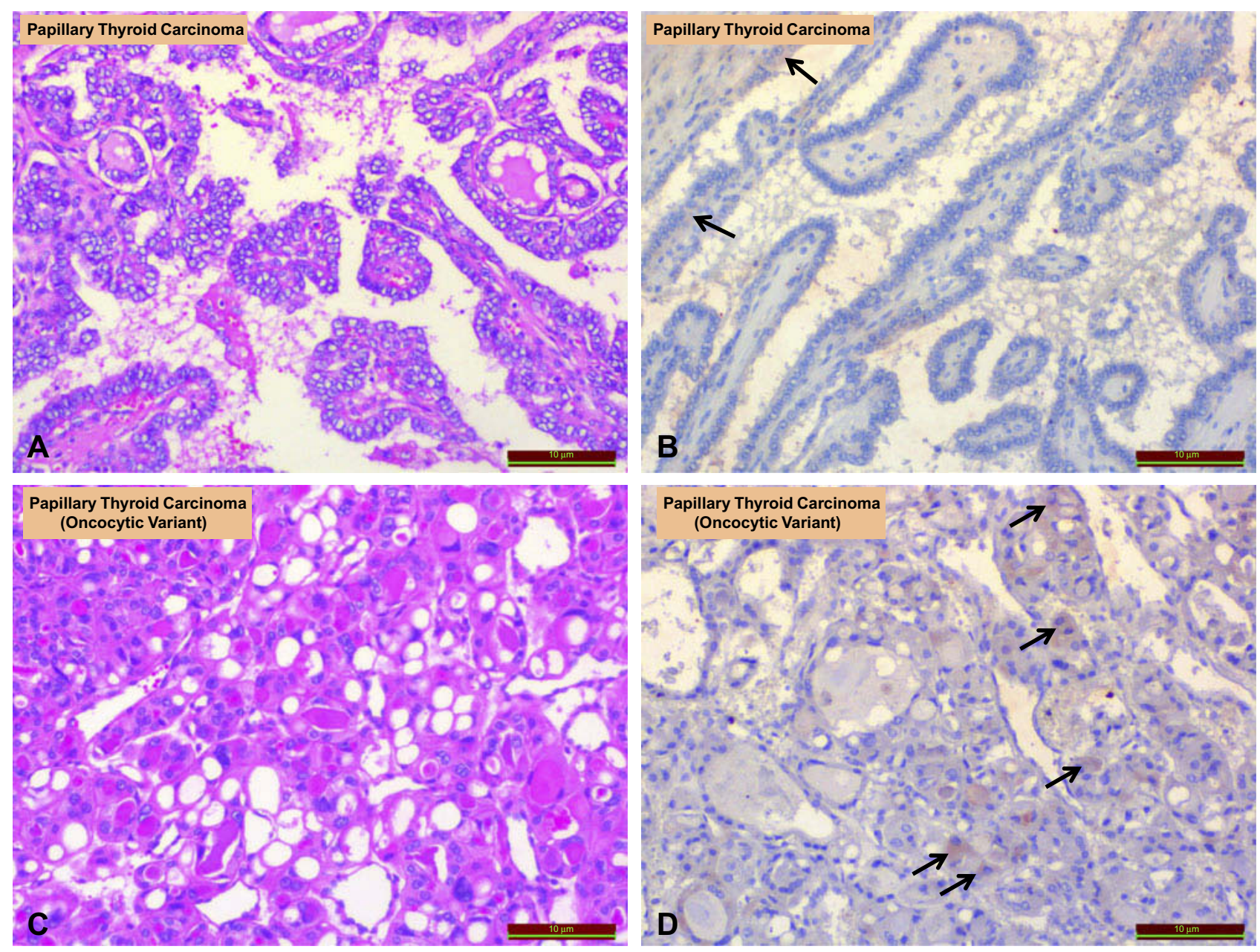

Figure 2 Comparison of irisin expression in papillary thyroid carcinoma and oncocytic papillary carcinoma. (A) Papillary thyroid carcinoma (H\&E staining). (B) Papillary thyroid carcinoma (irisin staining). (C) Oncocytic papillary carcinoma (H\&E staining). (D) Oncocytic papillary carcinoma (irisin staining). Arrows show irisin immunoreactivity (black arrows).

Abbreviation: H\&E, hematoxylin and eosin.

anti-inflammatory properties. ${ }^{39}$ In addition, increased irisin expression in Hashimoto's disease appears to be a novel candidate biomarker for the diagnosis of this disease in clinical settings. Furthermore, irisin immunoreactivity was significantly increased in oncocytic variants of papillary and FTC compared with papillary and MTC and controls. At least $75 \%$ of the oncocytic (thyroids showing oncocytic metaplasia developing after chronic irritation in the thyroid) follicular cells show a structure similar to Hurthle cells. ${ }^{42}$ Hurthle cells are oncocytic cells rich in mitochondria. ${ }^{42}$ In biological systems, being rich in mitochondria implies more energy production and, therefore, more ATP synthesis. ${ }^{43}$ However, increased irisin expression in oncocytic variants of thyroid tissues prevents ATP synthesis and releases heat. Apparently, by converting white adipose tissue into brown adipose tissue, irisin increases the level of uncoupling agents (UCP1, 2, and 3) in the mitochondria, leading to heat release. ${ }^{44}$ Cancer cells are vulnerable to heat. ${ }^{29}$ Thus, oncocytic variants of thyroid tissue rich in Hurthle cells, in other words, rich in mitochondria, produce more heat and cause death of oncocytic cells, thereby resulting in physiological homeostasis and apoptosis. ${ }^{42}$ However, since papillary and FTC tissues are not as rich in mitochondria as are their oncocytic variants, ${ }^{45,46}$ local heat generation due to irisin is not as much as that in oncocytic thyroid tissues; therefore, papillary and follicular thyroid carcinomas are more aggressive tumors with uncontrolled cell division. On the other hand it has been recently stated that in general, oncocytic/Hurthle cell TCs are expected to be more aggressive than papillary and follicular TCs. ${ }^{47}$

As known, rapidly dividing cells require more ATPs, tumor tissues in papillary and follicular thyroid 

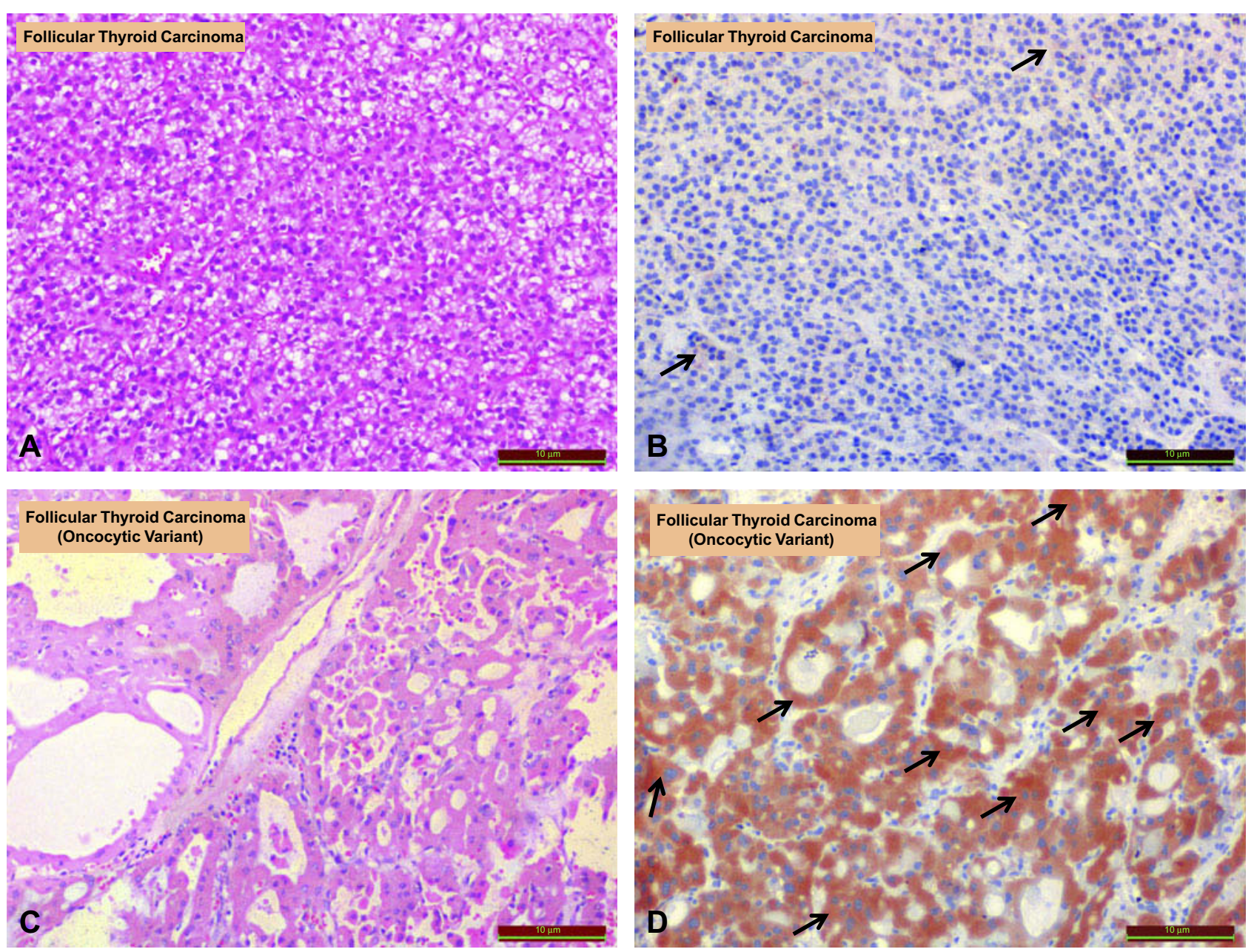

Figure 3 Comparison of irisin expression in follicular thyroid carcinoma and follicular thyroid carcinoma (oncocytic variant). (A) Follicular thyroid carcinoma (H\&E staining). (B) Follicular thyroid carcinoma (irisin staining). (C) Follicular thyroid carcinoma (oncocytic variant; H\&E staining). (D) Follicular thyroid carcinoma (oncocytic variant; irisin staining). Arrows show irisin immunoreactivity (black arrows).

Abbreviation: H\&E, hematoxylin and eosin.

carcinomas suppressed irisin synthesis in thyroid gland and thus increase and maintain the required ATP level, indicating that cancer cells modify energy pathways in their favor. $^{48}$ including metabolic shift (known as Warburg effect) toward alternative pathways of ATP synthesis. $^{48}$

In this study, we noted suppressed irisin expression in MTCs, which are more aggressive than papillary and follicular carcinomas. ${ }^{49}$ The more aggressive course of medullary thyroid cancers may be due to decreased irisin synthesis because irisin has been shown to confer antitumor effects in prostate and pancreatic cancer cell lines. $^{21,22}$ However, in this study, we cannot interpret the cause of significant increase in irisin expression in anaplastic thyroid cancer, which has a very poor prognosis. ${ }^{50}$ Moreover, since there are no other studies on this regard, we cannot compare our results against literature reports.
However, one explanation could be that in anaplastic thyroid cancer, cells may choose the path of energy restriction by increased irisin synthesis to control cancer. The risk of developing cancer in people who perform physical exercises is approximately $30-50 \%$ lower than those who do not. $^{24,51}$ This may be due to increase in irisin synthesis with exercise, which in turn exerts anti-tumor effects. In addition, since irisin has an anti-tumor function, irisin levels may increase in anaplastic thyroid cancer to suppress endothelial cell growth and induce the Bcl-2-linked apoptotic mechanism. ${ }^{21,22}$ Compared with controls, irisin levels may increase, decrease, or remains unchanged in certain cancerous tissues. Currently, the mechanisms underlying these effects remain unknown and important research questions remain to be studied.

In the present study, we found that irisin synthesized in nonmalignant thyroid tissues was produced by 

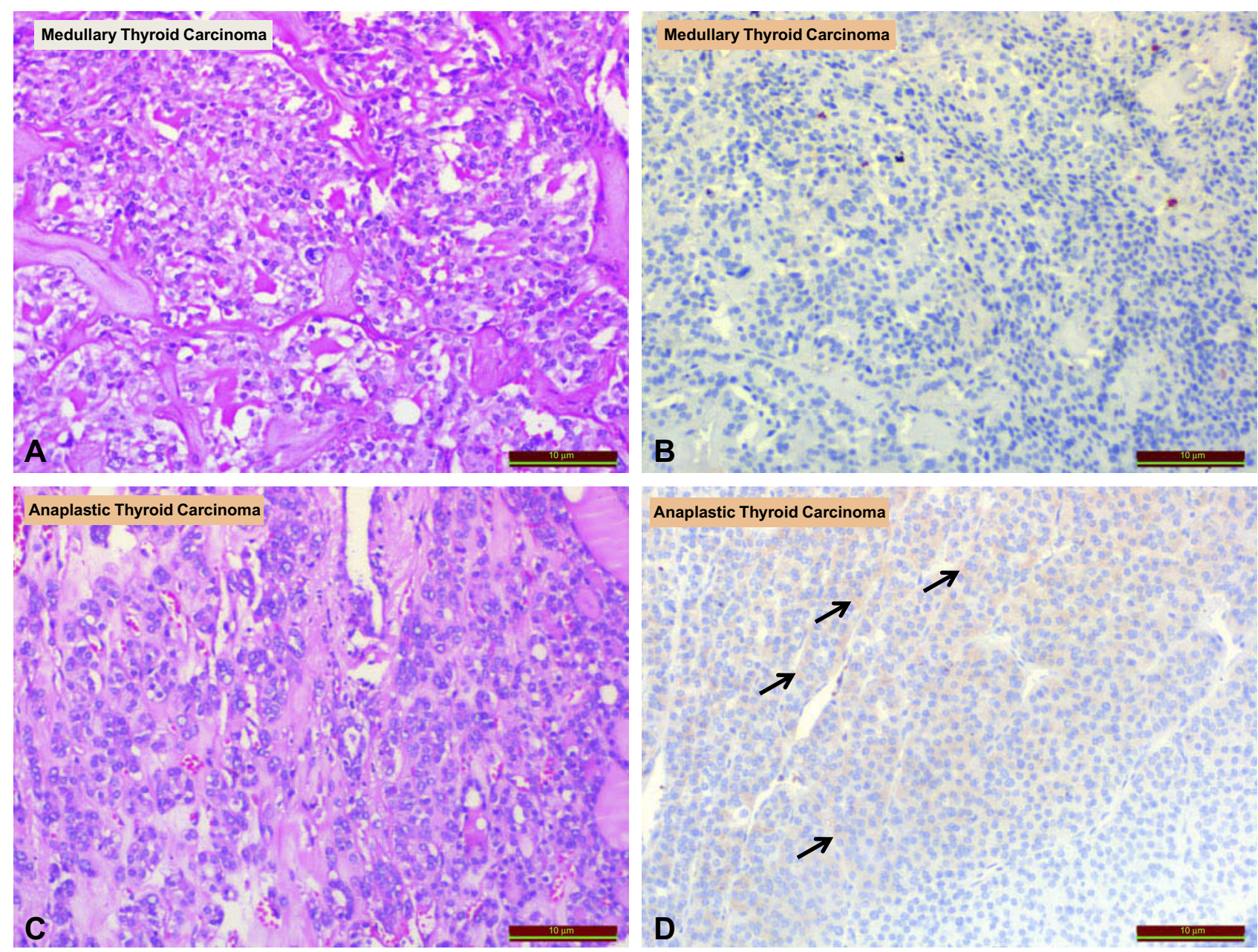

Figure 4 Comparison of irisin expression in medullary thyroid carcinoma and anaplastic thyroid carcinoma. (A) Medullary thyroid carcinoma (H\&E staining). (B) Medullary thyroid carcinoma (irisin staining). (C) Anaplastic thyroid carcinoma (H\&E staining). (D) Anaplastic thyroid carcinoma (irisin staining). Arrows show irisin immunoreactivity (black arrows).

Abbreviation: H\&E, hematoxylin and eosin.

follicular cells, as evidenced by irisin immunoreactivity in colloidal areas, which are secreted by follicular cells. ${ }^{52}$ Moreover, thyroid hormone is synthesized in the colloid. Unlike all other known endocrine glands, the thyroid hormone is produced in the follicles in the extracellular space. ${ }^{53}$ In this study, we suggest that irisin in colloidal areas is first synthesized by the follicular cells of the thyroid gland, which then enters and accumulates in the colloidal area. Therefore, irisin immunoreactivity was observed in follicular cells of the thyroid gland. In other words, follicular cells of the thyroid synthesize thyroid hormones as well as irisin. Irisin produced in thyroid tissue may act as a paracrine and autocrine hormone and even induce partial local heat generation since heat is released through irisin expression in the absence of ATP synthesis. ${ }^{12,14}$

\section{Conclusion}

This is a pioneering study demonstrating significantly increased irisin synthesis in oncocytic variants of thyroid carcinomas compared with that in other tumors of the thyroid gland. Moreover, we suggest that irisin immunoreactivity can be used as a biomarker for differentiating oncocytic variants of thyroid carcinomas from other types of thyroid cancer. Finally, our findings suggest that irisin is involved in carcinogenesis in the thyroid gland. Therefore, prospective studies that comprehensively elucidate the role of irisin in thyroid cancers are warranted to facilitate thyroid cancer treatment and diagnosis. Also, hypothesis that increased irisin expression in oncocytic variants of TC causes cell death through increased production of heat instead of ATP should be tested in cell culture models in the future. Overall, based on our results, future studies unveiling the role of irisin in thyroid cancers may lead the 
Table I Comparison of $\mathrm{H}$-scores among thyroid tissue series

\begin{tabular}{|c|c|c|c|}
\hline \multirow[t]{2}{*}{ Tissues } & \multicolumn{2}{|l|}{ H-score } & \multirow{2}{*}{$\begin{array}{l}\text { Irisin } \\
\text { amount } \\
\text { per mg of } \\
\text { tissue }\end{array}$} \\
\hline & $\begin{array}{l}\text { Benign } \\
\text { cells }\end{array}$ & Tumor cells & \\
\hline $\begin{array}{l}\text { Control thyroid } \\
\text { tissue }\end{array}$ & $0.22 \pm 0.13$ & - & $0.96 \pm 0.32$ \\
\hline HT & $0.67 \pm 0.15^{\mathrm{a}}$ & - & $1.26 \pm 0.32^{\mathrm{a}}$ \\
\hline PTC & - & $0.31 \pm 0.10^{b}$ & $1.44 \pm 0.42^{\mathrm{b}}$ \\
\hline OPTC & - & $0.80 \pm 0.20^{\mathrm{a}, \mathrm{c}}$ & $2.21 \pm 0.72^{\mathrm{a}, \mathrm{c}}$ \\
\hline FTC & - & $0.25 \pm 0.09^{\mathrm{b}, \mathrm{d}}$ & $1.1 \pm 0.38^{\mathrm{b}, \mathrm{d}}$ \\
\hline OFTC & - & $2.47 \pm 0.4^{\mathrm{a}, \mathrm{b}, \mathrm{c}, \mathrm{d}, \mathrm{e}}$ & $4.35 \pm 1.13^{\mathrm{a}, \mathrm{b}, \mathrm{c}, \mathrm{d}, \mathrm{e}}$ \\
\hline MTC & - & $0.00 \pm 0.00^{\mathrm{a}, \mathrm{b}, \mathrm{c}, \mathrm{d}, \mathrm{e}}$ & 0.05 \\
\hline ATC & - & $0.95 \pm 0.19^{\mathrm{a}, \mathrm{c}, \mathrm{e}}$ & $2.94 \pm 0.86^{\mathrm{a}, \mathrm{c}, \mathrm{e}}$ \\
\hline
\end{tabular}

Notes: ${ }^{a}$ Compared with control; ${ }^{b}$ compared with HT; 'compared with PTC; ${ }^{d}$ compared with oncocytic papillary thyroid carcinoma; and ${ }^{e}$ compared with FTC $(p<0.05)$. Data are presented as mean \pm SD.

Abbreviations: ATC, anaplastic thyroid carcinoma; FTC, follicular thyroid carcinoma; HT, Hashimoto's thyroiditis; MTC, medullary thyroid carcinoma; OFTC, oncocytic follicular thyroid carcinoma; OPTC, oncocytic papillary thyroid carcinoma; PTC, papillary thyroid carcinoma.

way to use of irisin as a potential target in the treatment along with its use in the diagnosis of thyroid cancers.

\section{Acknowledgment}

This study was presented as a poster in the 2nd Turkey in vitro Diagnostic, Disease and Health Biomarkers symposium held in İzmir on May 10-12, 2017, and was awarded the second place for the best scientific study in the poster category.

\section{Disclosure}

The authors report no conflicts of interest in this work.

\section{References}

1. Nguyen QT, Lee EJ, Huang MG, Park YI, Khullar A, Plodkowski RA. Diagnosis and treatment of patients with thyroid cancer. Am Health Drug Benefits. 2015;8(1):30-40.

2. Tumino D, Frasca F, Newbold K. Updates on the management of advanced, metastatic, and radioiodine refractory differentiated thyroid cancer. Front Endocrinol (Lausanne). 2017;8:312. doi:10.3389/ fendo.2017.00312

3. Udelsman R, Zhang Y. The epidemic of thyroid cancer in the United States: the role of endocrinologists and ultrasounds. Thyroid. 2014;24 (3):472-479. doi:10.1089/thy.2013.0257

4. Lamartina L, Grani G, Durante C, Filetti S. Recent advances in managing differentiated thyroid cancer. F1000Research. 2018;7:86.

5. WHO. Classification of tumours of the thyroid gland (2018). Available from: http://www.pathologyoutlines.com/imgau/thyroid/thyroidwho Bychkov01.jpg. Accessed January 2, 2019.

6. Mullur R, Liu YY, Brent GA. Thyroid hormone regulation of metabolism. Physiol Rev. 2014;94(2):355-382.

7. Gurgul E, Kasprzak A, Blaszczyk A, et al. Ghrelin and obestatin in thyroid gland - immunohistochemical expression in nodular goiter, papillary and medullary cancer. Folia Histochem Cytobiol. 2015;53(1):19-25.
8. Karaoglu A, Aydin S, Dagli AF, et al. Expression of obestatin and ghrelin in papillary thyroid carcinoma. Mol Cell Biochem. 2009;323 (1-2):113-118.

9. Zhang YF, Wang HN, Hong TP. Ghrelin expression in the tissues of different thyroid diseases. Beijing Dа Хие Хие Вао Yi Хие Ban. 2006;38(2):193-196.

10. Pisarev MA. Interrelationships between the pancreas and the thyroid. Curr Opin Endocrinol Diabetes Obes. 2010;17(5):437-439. doi:10.1097/MED.0b013e32833e0750

11. Di Pasquale M, Rothstein JL, Palazzo JP. Pathologic features of Hashimoto's-associated papillary thyroid carcinomas. Hum Pathol. 2001;32(1):24-30. doi:10.1053/hupa.2001.21138

12. Boström P, Wu J, Jedrychowski MP, et al. A PGC1- $\alpha$-dependent myokine that drives brown-fat-like development of white fat and thermogenesis. Nature. 2012;481(7382):463-468. doi:10.1038/ nature 10777

13. Aydin S, Kuloglu T, Aydin S, et al. A comprehensive immunohistochemical examination of the distribution of the fat-burning protein irisin in biological tissues. Peptides. 2014;61:130-136. doi:10.1016/j. peptides.2014.09.014

14. Aydin S. Three new players in energy regulation: preptin, adropin and irisin. Peptides. 2014;56:94-110. doi:10.1016/j.peptides.2014.03.021

15. Wang P, Ma HH, Hou XZ, Song LL, Song XL, Zhang JF. Reduced plasma level of irisin in first trimester as a risk factor for the development of gestational diabetes mellitus. Diabetes Res Clin Pract. 2018;142:130-138. doi:10.1016/j.diabres.2018.05.038

16. Zhao L, Li J, Li ZL, Yang J, Li ML, Wang GL. Circulating irisin is lower in gestational diabetes mellitus. Endocr J. 2015;62 (10):921-926. doi:10.1507/endocrj.EJ15-0230

17. Gizaw M, Anandakumar P, Debela T. A review on the role of irisin in insulin resistance and Type 2 diabetes mellitus. J Pharmacopuncture. 2017;20(4):235-242. doi:10.3831/KPI.2017.20.029

18. Park MJ, Kim DI, Choi JH, Heo YR, Park SH. New role of irisin in hepatocytes: the protective effect of hepatic steatosis in vitro. Cell Signal. 2015;27(9):1831-1839. doi:10.1016/j.cellsig.2015.04.010

19. Aydin S, Kuloglu T, Ozercan MR, et al. Irisin immunohistochemistry in gastrointestinal system cancers. Biotech Histochem. 2016;91 (4):242-250. doi:10.3109/10520295.2015.1136988

20. Kuloglu T, Celik O, Aydin S, et al. Irisin immunostaining characteristics of breast and ovarian cancer cells. Cell Mol Biol (Noisy-LeGrand). 2016;62(8):40-44.

21. Liu J, Song N, Huang Y, Chen Y. Irisin inhibits pancreatic cancer cell growth via the AMPK-mTOR pathway. Sci Rep. 2018;8(1):15247. doi:10.1038/s41598-018-33229-w

22. Tekin S, Erden Y, Sandal S, Yilmaz B. Is irisin an anticarcinogenic peptide? Med-Sci. 2015;4:2172-2180. doi:10.5455/medscience.2014. 03.8210

23. Manole E, Ceafalan LC, Popescu BO, Dumitru C, Bastian AE. Myokines as possible therapeutic targets in cancer cachexia. J Immunol Res. 2018;2018:8260742. doi:10.1155/2018/8260742

24. Aydin S. Is irisin a decisive protein in cancer cachexia and death of cancer cells? Eur Rev Med Pharmacol Sci. 2016;20(18): 3727-3729.

25. Zybek-Kocik A, Sawicka-Gutaj N, Szczepanek-Parulska E, et al. The association between irisin and muscle metabolism in different thyroid disorders. Clin Endocrinol (Oxf). 2018;88(3):460-467. doi:10.1111/ cen. 13527

26. Moon HS, Mantzoros CS. Regulation of cell proliferation and malignant potential by irisin in endometrial, colon, thyroid and esophageal cancer cell lines. Metabolism. 2014;63(2):188-193. doi:10.1016/j. metabol.2013.10.005

27. Brenmoehl J, Albrecht E, Komolka K, et al. Irisin is elevated in skeletal muscle and serum of mice immediately after acute exercise. Int J Biol Sci. 2014;10(3):338-349. doi:10.7150/ijbs. 7972

28. Silva JE. Thyroid hormone control of thermogenesis and energy balance. Thyroid. 1995;5(6):481-492. doi:10.1089/thy.1995.5.481 
29. Repasky EA, Evans SS, Dewhirst MW. Temperature matters! And why it should matter to tumor immunologists. Cancer Immunol Res. 2013;1(4):210-216. doi:10.1158/2326-6066.CIR-13-0118

30. Haymart MR, Esfandiari NH, Stang MT, Sosa JA. Controversies in the management of low-risk differentiated thyroid cancer. Endocr Rev. 2017;38(4):351-378. doi:10.1210/er.2017-00067

31. Katoh H, Yamashita K, Enomoto T, Watanabe M. Classification and general considerations of thyroid cancer. Ann Clin Pathol. 2015;3 (1): 1045

32. Kakudo E, Satoh S, Inomata K, Kagiya T, Yamashita H, Lai CR. Papillary thyroid neoplasms in the 4th edition WHO classification of tumors of endocrine organs: neoplasms with papillary thyroid carcinoma-type nuclear features. JBCM. 2018;7(1):21-35.

33. Hsu SM, Raine L, Fanger H. Use of avidin-biotin-peroxidase complex (abc) in immunoperoxidase techniques-a comparison between ABC and unlabeled antibody (pap) procedures. $J$ Histochem Cytochem. 1981;29:577-580. doi:10.1177/29.4.6166661

34. Chen Z, Wang T, Cai L, et al. Clinicopathological significance of non-small cell lung cancer with high prevalence of Oct- 4 tumor cells. J Exp Clin Cancer Res. 2012;31:10. doi:10.1186/1756-996631-95

35. Aydin S, Ozercan IH, Dagli F, et al. Ghrelin immunohistochemistry of gastric adenocarcinoma and mucoepidermoid carcinoma of salivary gland. Biotech Histochem. 2005;80(3-4):163-168. doi:10.1080/ 10520290500387847

36. Aydin S, Kuloglu T, Aydin S, et al. Cardiac, skeletal muscle and serum irisin responses to with or without water exercise in young and old male rats: cardiac muscle produces more irisin than skeletal muscle. Peptides. 2014;52:68-73. doi:10.1016/j.peptides.2013.11.024

37. Brehar AC, Brehar FM, Bulgar AC, Dumitrache C. Genetic and epigenetic alterations in differentiated thyroid carcinoma. $\mathrm{J} \mathrm{Med}$ Life. 2013;6(4):403-408.

38. Fröhlich E, Wahl R. Thyroid autoimmunity: role of anti-thyroid antibodies in thyroid and extra-thyroidal diseases. Front Immunol. 2017;8:521.

39. Mazur-Bialy AI, Pocheć E, Zarawski M. Anti-inflammatory properties of irisin, mediator of physical activity, are connected with TLR4/ MyD88 signaling pathway activation. Int J Mol Sci. 2017;18(4): E701.
40. Uc ZA, Gorar S, Mizrak S, Gullu S. Irisin levels increase after treatment in patients with newly diagnosed hashimoto thyroiditis. J Endocrinol Invest. 2019;42(2)175-181.

41. Bakal U, Aydin S, Sarac M, et al. Serum, Saliva, and Urine Irisin with and without acute appendicitis and abdominal pain. Biochem Insights. 2016;9:11-17.

42. Cannon J. The significance of hurthle cells in thyroid disease. Oncologist. 2011;16(10):1380-1387.

43. Picard M, McEwen BS, Epel ES, Sandi C. An energetic view of stress: focus on mitochondria. Front Neuroendocrinol. 2018;49: 72-85.

44. Ost M, Keipert S, Klaus S. Targeted mitochondrial uncoupling beyond UCP1 - the fine line between death and metabolic health. Biochimie. 2017;134:77-85

45. Asa SL. My approach to oncocytic tumours of the thyroid. J Clin Pathol. 2004;57(3):225-232.

46. Zhang J, Yu W, Ryu SW, et al. Cardiolipins are biomarkers of mitochondria-rich thyroid oncocytic tumors. Cancer Res. 2016;76 (22):6588-6597.

47. JanovitzJustine T, Barletta A. Clinically relevant prognostic parameters in differentiated thyroid carcinoma. Endocr Pathol. 2018;29 (4):357-364.

48. Liberti MV, Locasale JW. The warburg effect: how does it benefit cancer cells? Trends Biochem Sci. 2016;41(3):211-218.

49. Aboelnaga EM, Ahmed RA. Difference between papillary and follicular thyroid carcinoma outcomes: an experience from Egyptian institution. Cancer Biol Med. 2015;12(1):53-59.

50. Liu TR, Xiao ZW, Xu HN, et al. Treatment and prognosis of anaplastic thyroid carcinoma: a clinical study of 50 cases. PLoS One. 2016;11(10):e0164840.

51. Gilbert A, Czarkowska-Paczek B, Deptała A. Physical activity in prevention and treatment of colon cancer. Przegl Lek. 2013;70: 969-972.

52. Wissig SL. The anatomy of secretion in the follicular cells of the thyroid gland. I. The fine structure of the gland in the normal rat. J Biophys Biochem Cytol. 1960;7:419-432.

53. Chen C, Xie Z, Shen Y, Xia SF. The roles of thyroid and thyroid hormone in pancreas: physiology and pathology. Int $J$ Endocrinol. 2018;2018:2861034.

\section{Publish your work in this journal}

Cancer Management and Research is an international, peer-reviewed open access journal focusing on cancer research and the optimal use of preventative and integrated treatment interventions to achieve improved outcomes, enhanced survival and quality of life for the cancer patient.
The manuscript management system is completely online and includes a very quick and fair peer-review system, which is all easy to use. Visit http://www.dovepress.com/testimonials.php to read real quotes from published authors. 